\title{
Bed bugs in hospitals: more than just a nuisance
}

$\mathrm{B}$ ed bugs are everywhere. They are in college dorms and movie theatres. They are in libraries and taxis. And you might even find one in your local hospital.

There are no infestation figures for Canadian hospitals, but in the United States, more than a third of pestmanagement companies responded to bed bug infestations in hospitals in 2012, up by more than $50 \%$ from 2011 , according to this year's bed bug survey released by the National Pest Management Association. The number of exterminators used in nursing homes has also increased, from $25 \%$ in 2011 to $46 \%$ in 2012.

In Canada, the most recent hospital infestations were reported in Hamilton, Ontario. Hamilton Health Sciences hospitals had 10 cases between January and July 2012, and 3 cases were reported at the Charlton Avenue location of St. Joseph's Healthcare.

But many more hospitals likely harbour the pests, given that Toronto and Vancouver rank third and eighth respectively on a top-10 list of most-infested cities in North America, according to Insight Pharmaceuticals.

"The numbers are humongous across the country," says Don McCarthy, president of Braemar Pest Control in Bedford, Nova Scotia. "They're in apartments and homes, and that of course trickles down to hospitals."

He says the bugs get into hospitals three ways: emergency situations where people are picked up from their homes, from patients' clothing and personal articles, and from people visiting patients.

According to Dr. Joel Kettner, scien-

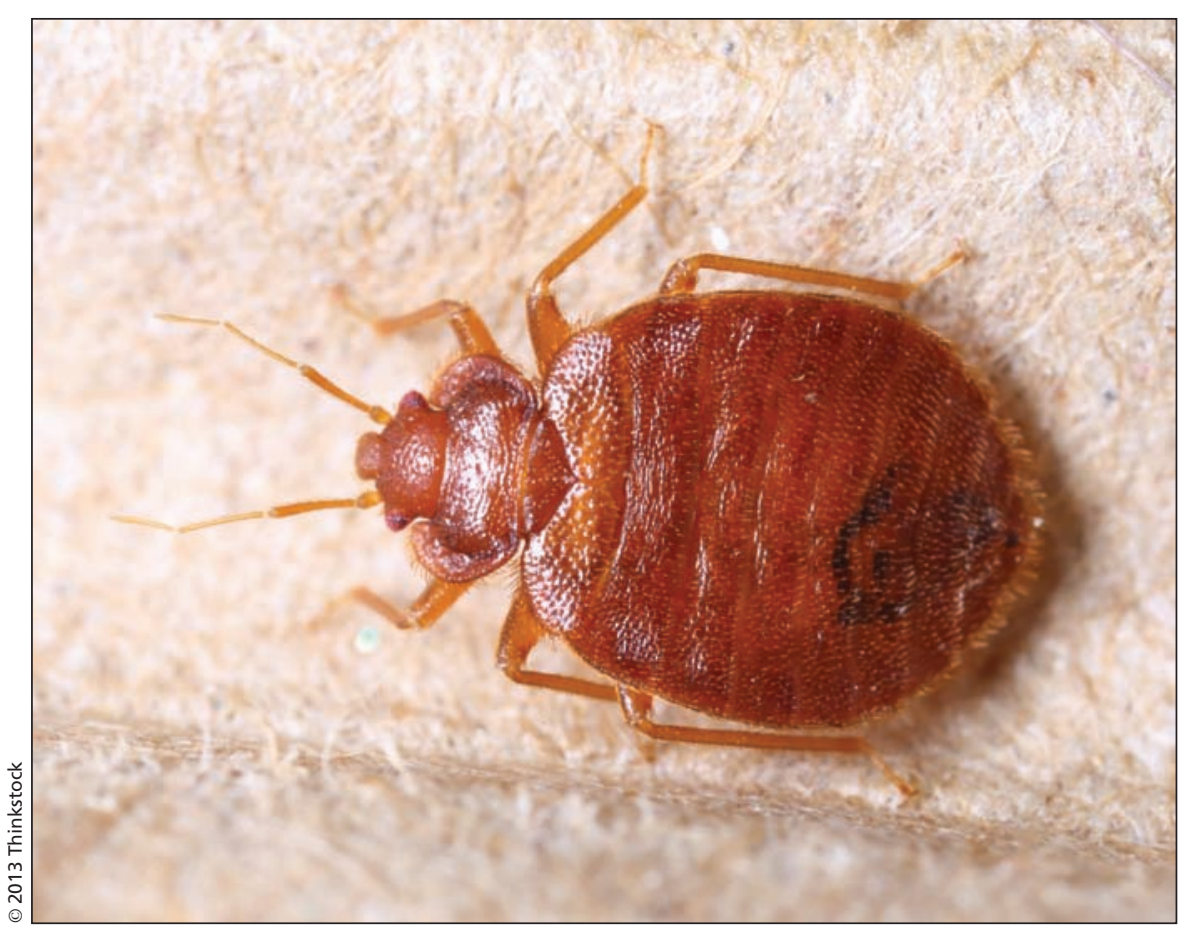

In the United States, more than a third of pest-management companies responded to bed bug infestations in hospitals in 2012.

tific director for the National Collaborating Centre for Infectious Disease in Winnipeg, Manitoba, hospital infestations are difficult to measure because there are no surveillance procedures and there is little research on the subject outside of pest control companies. But the ick factor could be enough to lead patients to go elsewhere.

"Hospitals need to appear clean, as well as be clean, to give confidence to people," says Kettner.

Bed bugs are generally not considered to be a health hazard, although there has been at least one documented case of anemia (www.cmaj.ca/content /181/5/287.full). Still, the itchy welts they leave can be a problem for patients.

"Like any insect, they bite. That can cause a reaction and if you scratch it, it can get infected," says Kettner.

Luckily, according to McCarthy, treating an infestation in a hospital is actually easier than other locations. He says the whole process can take less than a day.

"Hospitals are designed to be clean, especially emergency rooms. The beds are changed every day, and insects don't have the chance to stick around," says McCarthy. — Jasmine Williams, CMAJ

CMAJ 2013. DOI:10.1503/cmaj.109-4491 